\title{
Molecular characterization of a Candidatus Phytoplasma aurantifolia-related strain associated with Zinnia elegans phyllody disease in Iran
}

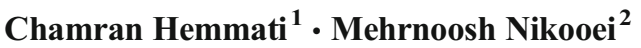

Received: 17 January 2017 / Accepted: 3 February 2017 / Published online: 21 February 2017

(C) Australasian Plant Pathology Society Inc. 2017

\begin{abstract}
Zinnia elegans plants showing symptoms of phyllody, virescence, witches' broom, little leaf and yellowing were observed in Bandar Abbas, Hormozgan Province, Iran. Analysis showed that the phytoplasma shares a $99 \%$ sequence identity with "Candidatus Phytoplasma aurantifolia" and is a strain related to this species. To the authors' knowledge, this is the first report of the occurrence of a 16SrII phytoplasma infecting Zinnia elegans flowers.
\end{abstract}

Keywords Zinnia elegans · 16 SrII · Phyllody and witches" broom $\cdot$ Hormozgan

Phytoplasmas are non-helical, cell wall-less phyto-pathogenic bacteria, belonging to the Mollicutes class

Chamran Hemmati

Chamran.hemmati@gmail.com

Department of Entomology, Faculty of Agriculture, Tarbiat Modares University, Tehran, Iran

2 Department of Agriculture, Faculty of Agriculture and Natural resources, University of Hormozgan, Bandar Abbas, Iran
(Firrao et al., 2005) that can cause devastating yield loss in diverse low and high value crops worldwide. For instance, lime witches' broom disease (16SrII group phytoplasma) has been considered as one of the most destructive diseases in southern Iran, with aapproximate losses of US\$ 27 million in 2007 (Mardi et al. 2007). These plant pathogens inhabit the sieve cells of phloem tissue and induce disease symptoms such as virescence, phyllody, sterility of flowers, proliferation of auxiliary or axillary shoots, abnormal elongation of internodes, generalized stunting and unseasonal yellowing or reddening of the leaves (Du Toit 2014).

Zinnia, belonging to family Asteraceae, is an annual plant and notable for its solitary long-stemmed flowers coming in a variety of bright colors. Zinnia elegans is the most familiar species, which originates from Mexico and is thus a warm-hot climate plant. In Iran, especially in the southern region, this species is widely planted as ornamental plants in municipal lands and parks.

In December 2016, typical symptoms of phytoplasma disease, including phyllody, virescence, witches" broom, little leaf and yellowing, were observed in Zinnia elegans planted in Bandar Abbas, Hormozgan province, Iran. The aim of this study was to identify the causal agent of this $Z$. elegans associated disease in Bandar Abbas, Iran. 
Samples of both symptomatic and symptomless Z. elegans plants were collected from Bandar Abbas, Iran. Total DNA was extracted separately from $1 \mathrm{~g}$ of flowers and leaves of five symptom-bearing (Fig. 1a, b) and two symptomless (Fig. 1c) using an adjusted cetyltrimethylammonium bromide (CTAB) method (Doyle and Doyle 1990). Both direct and nested PCR assays were performed for detection of phytoplasma DNA using phytoplasma universal 16S rDNA primer pairs P1/P7 (Deng and Hiruki 1991; Schneider et al. 1995) and R16F2n/R16R2 (Gundersen and Lee, 1966), amplifying fragments of ca. $1800 \mathrm{bp}$ and $1250 \mathrm{bp}$, respectively (Deng and Hiruki, 1991). Following sequencing of the PCR products obtained, these sequences were checked and aligned using the softwares DNAstar and ClustalX. Phylogenetic analyses were conducted by neighbor joining (NJ) methods using MEGA 6.0 software (Tamura et al. 2013). The $16 \mathrm{~S}$ rDNA gene sequences for other phytoplasmas used in the comprehensive phylogenetic analyses were retrieved from GenBank.

PCR products of 1800 and 1250 bp were obtained following direct and nested PCR from all five symptom-bearing plants but not from symptomless plants and PCR products from two plants were directly sequenced and deposited in GenBank (Acc. No. KY501142; KY501143). BLAST analysis of the 16S
rDNA sequences revealed that the phytoplasma associated with Zinnia elegans phyllody (ZeP) shared 99\% identity with phytoplasmas in the 16SrII phylogenetic group, "Candidatus Phytoplasma aurantifolia" such as Alfalfa witches" broom phytoplasma (KT634120). The phylogenetic neighbour-joining tree (MEGA 6 software) based on the partial 16S rDNA sequences (1260 bp) of the ZeP phytoplasma and several reference phytoplasmas supported these results and showed that the ZeP phytoplasma belongs to the 'Candidatus Phytoplasma aurantifolia' clade (Fig. 2).

In Iran, group16SrII phytoplasmas have been identified as causal agent of many diseases such as witches" broom disease of lime (WBDL), cabbage yellow, clover little leaf, alfalfa witches" broom, tomato witches" broom, sunflower phyllody, cucumber and squash phyllody, carrot witches" broom, parsley witches" broom, pomegranate little leaf and bell pepper big bud. Association between phytoplasmas and Zinnia elegans were previously reported by Wang and Hiruki (2001) and Singh et al. (2011) who demonstrated that "Candidatus Phytoplamsa asteris"-related strains could infect this species in Canada and India, respectively. However, to our knowledge, this is the first report of an association between "Candidatus Phytoplasma aurantifolia"-related strain and Z. elegans in Iran or worldwide.

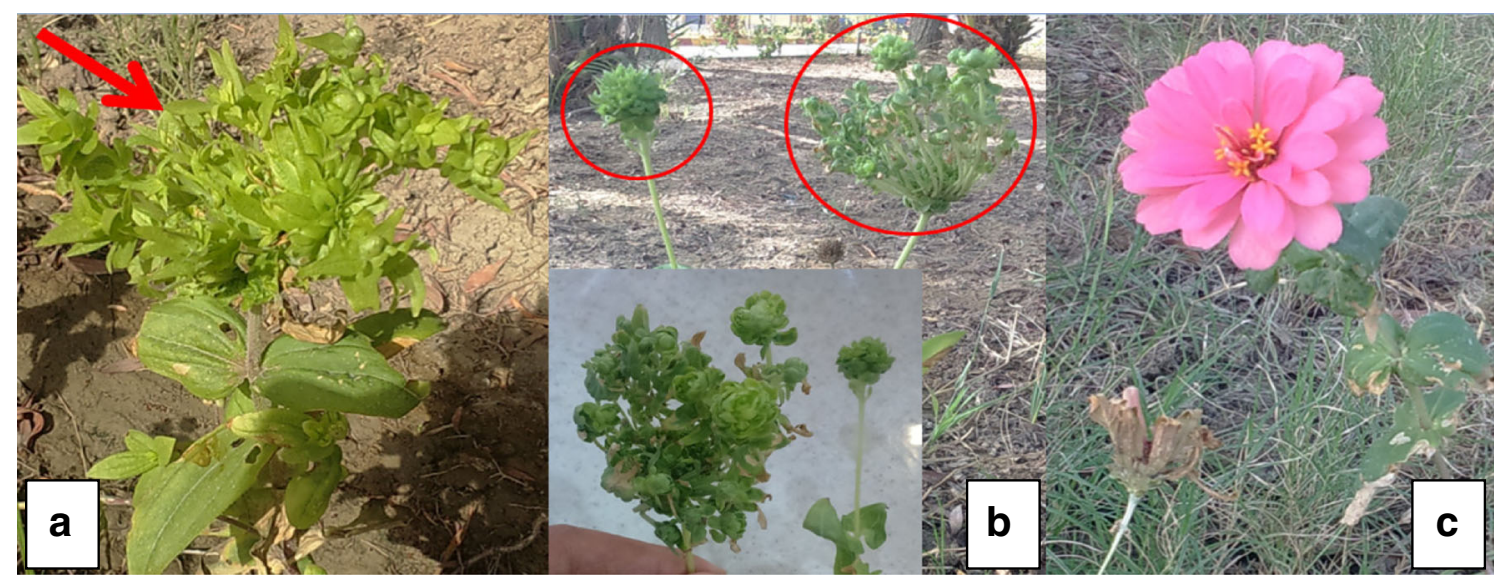

Fig. 1 Symptoms of witches" broom, little leaf and yellowing (shown by red arrow) (a), virescence and phyllody (shown in red circle) (b) in comparison with healthy Zinnia elegans (c) 


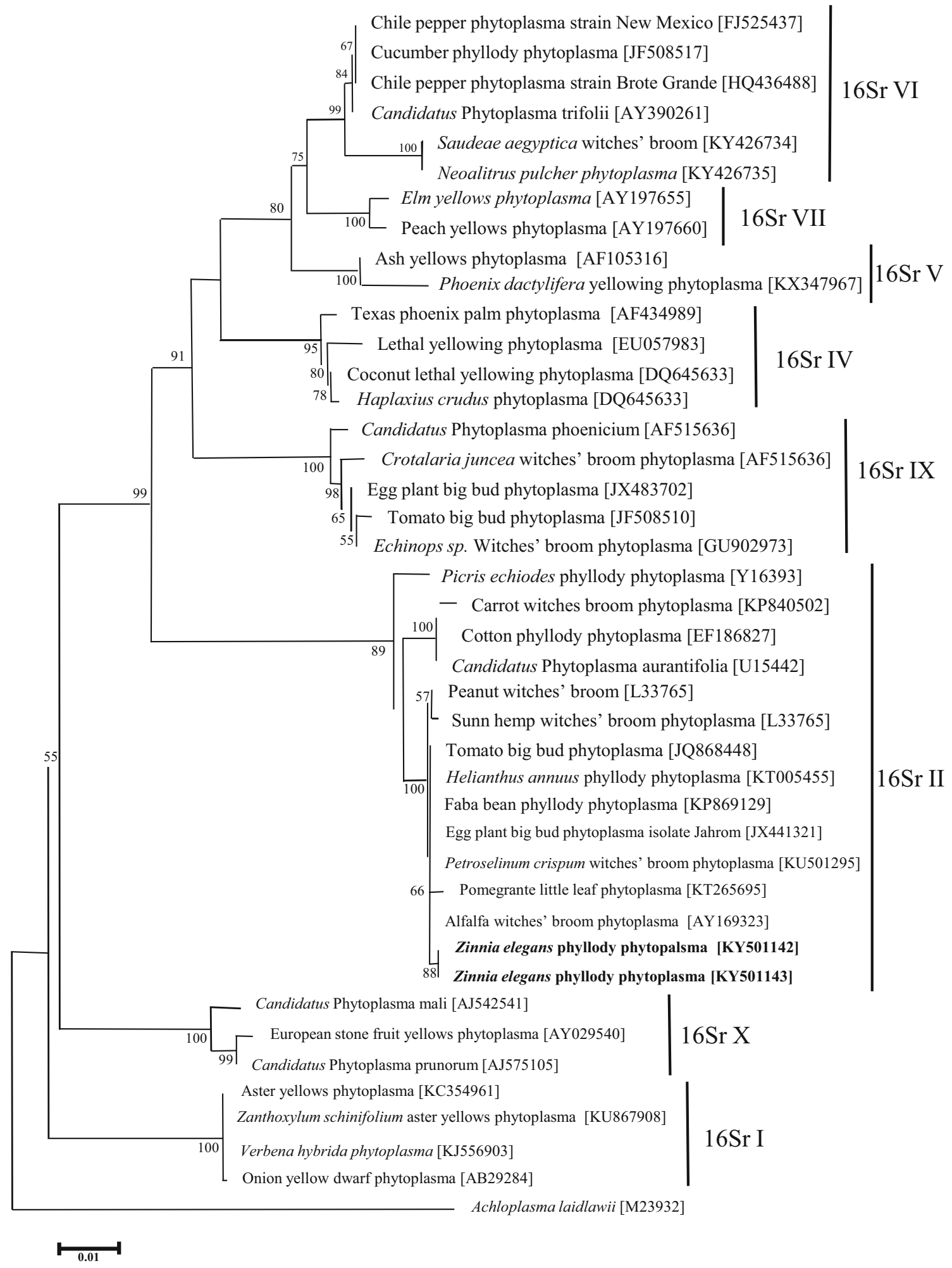

Fig. 2 Phylogenetic tree of partial 16S rDNA gene sequence from Zinnia elegans phyllody phytoplasma isolates (marked by bold face type) and selected phytoplasma reference sequences. GenBank accession numbers are shown in brackets, and $16 \mathrm{Sr}$ groups are annotated to the right.
Acholeplasma laidlawii was used as outgroup to root the tree. The tree was constructed by the neighbor-joining method using MEGA 6 software. The bar indicates the number of nucleotide substitution per site. Bootstrap values are shown at nodes with greater than 50\% support 


\section{References}

Deng S, Hiruki C (1991) Amplification of 16Sr RNA genes from culturable and non-culturable mollicutes. J Microbiol Methods 14: $53-61$

Doyle JJ, Doyle JL (1990) Isolation of plant DNA from fresh tissue. Focus 12:3-15

Du Toit A (2014) Phytoplasma converts plants into zombies. Nat Rev Microbiol 12:393-395

Firrao G, Gibb K, Streten C (2005) Short taxonomic guide to the genus 'Candidatus phytoplasma'. J Plant Pathol 87:249-263

Gundersen DE, Lee IM (1966) Ultrasensitive detection of phytoplasma by nested-PCR assays using two universal primer sets. Phytopathol Mediterr 35:144-151

Mardi M, Khayam Nekouei M, Majidi E, Rahimian H, Izadpanah K, Shokatfadaee M, Louni A, Hasanpour A, Aghajanzadeh S, Darabi H, Ebrahimi Y, Salehi M., Khoshkam S, Osfoori R, Ahmadi K, Abdi S, (2007) Comprehensive Management Program for Witches'
Broom Disease of Lime. Nashr-e Amozesh Keshavarzi Publisher, Karaj, Iran

Schneider B, Seemuller E, Smart CD, Kirkpatrick BC (1995) Phylogenetic classification of plant pathogenic mycoplasma-like organism or phytoplasma. In: Razin S, Tully JG (eds) Molecular and diagnostic procedures in Mycoplasmology. Academic press, New York, pp 369-380

Singh M, Chaturvedi Y, Tewari AK, Rao GP, Snehi SK, Raj SK, Khan MS (2011) Diversity among phytoplasmas infecting ornamental plants grown in India. Bull Insectol 64:69-70

Tamura K, Stecher G, Peterson D, Filipski A, Kumar S (2013) MEGA6: molecular evolutionary genetics analysis, version 6.0. Mol Biol Evol 30:2725-2729

Wang K, Hiruki C (2001) Use of heteroduplex mobility assay for identification and differentiation of phytoplasmas in the aster yellows group and the clover proliferation group. Phytopathology 91(6): $546-552$ 